\title{
Dilemmas associated with local allergic rhinitis
}

\author{
Edyta Krzych-Fałta, Andrzej Namysłowski, Bolesław Samoliński
}

Unit of Environmental Hazard Prevention and Allergology, Faculty of Health Sciences, Medical University of Warsaw, Warsaw, Poland

Adv Dermatol Allergol 2018; XXXV (3): 243-245

DOI: https://doi.org/10.5114/ada.2018.76215

\begin{abstract}
Local allergic rhinitis (LAR) in patients with no systemic markers of atopy is a very interesting phenomenon due to the lack of any definitive explanation for the mechanism of this IgE-dependent reaction. Some of the recent attempts to explain this phenomenon consider LAR to be closely associated with an allergic reaction, some suggest that this phenomenon is a spontaneous process in the nasal mucosa. Future attempts to elucidate the complexity of inflammatory reactions will undoubtedly establish a clear differential diagnostics algorithm for rhinitis.
\end{abstract}

Key words: rhinitis, local allergic reaction, nasal cavity.

\section{Introduction}

Defined as inflammation of the nasal mucosa, rhinitis is a condition that poses a number of clinical and research problems, due to its unclear categorization [1]. Rhinitis can be of one of three basic clinical types: allergic rhinitis $(A R)$, infectious rhinitis, and non-allergic non-infectious rhinitis (NANIR) [2]. While in the case of AR, which can be definitively diagnosed via skin-prick tests (specific IgE) and whose pathomechanism is clearly understood, the other rhinitis types constitute a group of conditions, which, due to a lack of available diagnostic tools, are very difficult to study. Moreover, as can be seen in the very definition of rhinitis "...it is (an) inflammation ...", which refers to all types of rhinitis, many of which lack the presence of inflammatory cells [1].

The Epidemiology of Allergic Disorders in Poland (ECAP) study demonstrated that up to $40 \%$ of the general population $(39.7 \%$ of the urban population and $21.6 \%$ of the rural population, aged $6-7$, suffer from rhinitis; with only $3.7 \%$ of rural and $24.3 \%$ of urban residents diagnosed with AR, children aged $13-14,36.2 \%$ of urban and $22.1 \%$ of rural residents, adults $37.6 \%$ of urban and $23.8 \%$ of rural residents) [3]. This leads to the conclusion that up to $16.4 \%$ of rhinitis patients are classified as suffering from NANIR, usually chronic NANIR. An average of $44-87 \%$ of patients diagnosed with AR have been shown to have concomitant NANIR, which proves the need to distinguish another type of rhinitis, where a confirmed allergy does not preclude the risk of concomitant NANIR, and conversely, a history of atopy without a clear causal relationship does not preclude NANIR $[1,4]$. What constitutes a particularly interesting problem in terms of rhinitis classification is local allergic rhinitis (LAR), which constitutes $8-20 \%$ of all rhinitis cases $[5,6]$.

\section{Aim}

The objective of this study was to gain a better understanding of rhinitis classification and emphasize the key role of IgE in LAR. Local allergic rhinitis is responsible for a significant share of rhinitis manifestations in patients diagnosed with NANIR. In fact, this is AR with local manifestations in the nasal mucosa involving slgE production, however, with an absence of immunoglobulins $E$ in other organs, particularly in the skin and blood serum.

\section{Local allergic rhinitis}

In patients with NANIR, LAR occurs periodically or chronically, which is confirmed by nasal lavage fluid tests for inflammatory markers [7]. Interestingly, studies on mice challenged with ragweed pollen without prior systemic immunization demonstrated a potential risk of the IgE-dependent reaction converting from local to systemic (affecting distant organs and systems) [8, 9]. Week three of continual exposure to ragweed pollen produced systemic atopy, which eventually led to pneumonia [10]. These studies show that 'entopic' individuals (i.e. those diagnosed with NANIR and LAR) may be at risk of a systemic IgE-dependent reaction, with LAR itself being a specific herald of systemic sensitization. Simi-

Address for correspondence: Dr. Edyta Krzych-Fałta, Unit of Environmental Hazard Prevention and Allergology, Faculty of Health Sciences, Medical University of Warsaw, 1 a Banacha St, 02-097 Warsaw, Poland, phone: +48 2259910 40, fax: +48 225992042 , e-mail: e.krzych@gmail.com Received: 28.02.2017, accepted: 13.04.2017. 


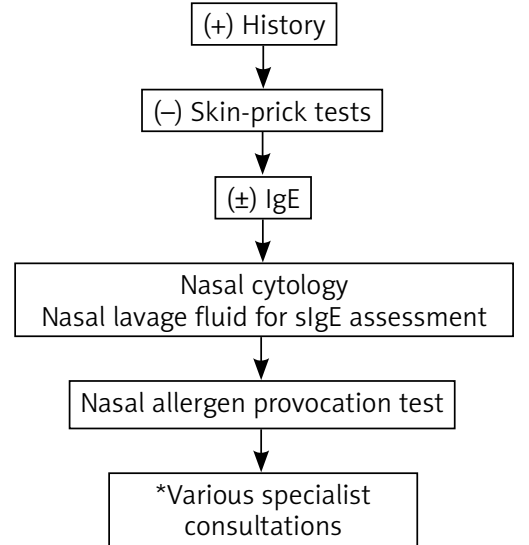

*Parasites and other conditions with high IgE levels.

Figure 1. Diagnostic algorithm for local allergic rhinitis

larly, a study in human subjects by Rondón et al. showed a positive reaction in skin-prick tests and serum slgE over several years of follow-up in LAR groups [7].

Due to the scarcity of literature reports on the topic, there have been no definitive descriptions of AR types, which would include LAR. Our current understanding of the role of Th2 cells, locally produced class E immunoglobulins [11], and eosinophil, mast cell, as well as CD3+ and CD4+ T-cell accumulation [2, 7] does not fully encompass the important role of IgE in rhinitis patients. This is a diagnostically challenging group (Figure 1). Non-allergic non-infectious rhinitis diagnostics tends to be based on exclusion and the sub-phenotyping is difficult due to a number of various factors that trigger LAR [2]. Apart from the basophil activation test (BAT) and exfoliative cytology, nasal allergen provocation testing (NAPT) is the only diagnostic modality that helps determine which patients are at the highest risk of LAR based on reaction intensity [3]. What is analyzed is the samples of nasal lavage fluid, which are centrifuged, with the resulting supernatant assessed using the CAP technique.

Nasal mucosa reaction to the administered allergen is immediate and occurs mostly by stimulation of immunoglobulin-coated cells (mast cells, macrophages). This results in the secretion of inflammatory mediators, i.e. tryptase, histamine, CysLT, and PGD [12], which in turn stimulate the local sensory nerve and vascular receptors within the nasal mucosa. Mast cells secrete chemotactic agents and platelet activating factor (PAF), which contribute to the development of inflammation [12]. The immediate-phase reaction typically lasts approximately up to 20-30 min and may evolve into a late-phase reaction, which begins about $4 \mathrm{~h}$ after nasal allergen application. The late-phase reaction is characterized by a release of cytokines and chemokines into the bloodstream, which leads to egress of eosinophils from the bone marrow.
These eosinophils secrete eosinophil cationic protein (ECP) and major basis protein (MBP), whose levels correlate closely with the manifestations of a late-phase reaction. As a result of those changes, increased serum IL-5 levels together with transportation of this interleukin into the pulmonary circulation cause increased exhaled nitric oxide (eNO) levels and bronchial hyper-reactiveness [12]. The fact that IL-5 takes part in the pathomechanism of the IgE-dependent reaction in NANIR patients has been demonstrated in both mouse and human studies, which showed significantly increased IL-5 levels in the nasal lavage fluid $[13,14]$. An NAPT study by Rondón et al. on a group of 50 (adult) patients diagnosed with idiopathic rhinitis showed significantly increased levels of inflammatory markers both in the nasal lavage fluid and in blood serum in comparison with those in the control group, and less increased levels in comparison with those in patients diagnosed with AR [7]. Conversely, in the youngest group diagnosed with LAR, NAPT with a house dust mite extract showed no significant increase in tryptase or slgE levels in the nasal lavage fluid. Moreover, the proportion of patients diagnosed with bronchial asthma was as high as 38.9\% [15].

Rondón et al. define LAR as a reaction associated with local slgE production and a positive response to NAPT [7]. Gelardi et al. classify LAR as a spontaneous process involving inflammatory markers, without NAPT. Interestingly, slgE was shown to be present in the nasal lavage fluid both in the healthy controls and in the group with non-allergic rhinitis (NAR) $(n=12)$ In the combined group of NAR and control patients, LAR was observed in 67.9\% (parietaria), $26.8 \%$ (olive), $15.4 \%$ (cypress), $60.7 \%$ (dust mites), and $38.1 \%$ (grasses) of patients. It should be noted that it was only in the case of parietaria allergens that a significant difference between the study groups was observed, with $73.3 \%$ of the AR group vs. $25 \%$ of NAR patients and $42.9 \%$ of controls exhibiting LAR ( $p<0.04)$. Moreover, nasal cytology confirmed the hypotheses proposed by the authors on the role of spontaneous processes in LAR pathomechanism: in the NAR vs. AR groups, neutrophils $303.4 \pm 19.3$ vs. $502.5 \pm 24.4$, respectively ( $p<0.001$ ); eosinophils $82.5 \pm 10.4$ vs. 59.4 \pm 7.9 , respectively; lymphocytes $8.7 \pm 3.9$ vs. $34.5 \pm 5.9$, respectively ( $p<0.001$ ), mast cells $28.5 \pm 6.3$ vs. $10.3 \pm 3.7$, respectively $(p<0.001)[16]$.

\section{Conclusions}

Since the mechanism of LAR has not been fully understood and the relevant literature reports are scarce, there is an urgent need to continue studies on this topic. A critical comparative analysis, particularly one including nasal lavage fluid assessment both following NAPT and with no NAPT, should help explain the role of an IgEdependent response in LAR. 


\section{Conflict of interest}

The authors declare no conflict of interest.

\section{References}

1. Grzanka A, Jarząb J, Śliwińska-Kowalska M, et al. Wątpliwości nomenklaturowe i klasyfikacyjne niealergicznych nieżytów nosa. Otolaryngologia 2010; 9: 45-9.

2. Fornal R, Kurzawa R, Błażowski Ł, et al. Nieżyty nosa najważniejsze fenotypy i endotypy oraz zasady leczenia. Alergia Astma Immunol Klin 2015; 20: 242-52.

3. Samoliński B, Raciborski F, Lipiec A, et al. Epidemiologia chorób w Polsce (ECAP). Alergol Pol/Pol J Allergol 2014; 1: 10-8.

4. Wallace DV, Dykewicz MS, Bernstein DI, et al. The diagnosis and management of rhinitis: an update practice parameter. J Allergy Clin Immunol 2008; 122 (Suppl): S1-84.

5. Mazurek H, Modrzynski M. Nasal challenge tests with allergens versus other allergy and rhinitis diagnostic tests. Postep Dermatol Allergol 2010; 27: 193-5.

6. Rondón C, Campo P, Herrera R, et al. Nasal allergen provocation test with multiple aeroallergens detects polysensitization in local allergic rhinitis. J Allergy Clin Immunol 2011; 128: 1192-7.

7. Rondón C, Fernández J, López S, et al. Nasal inflammatory mediators and specific lgE production after nasal challenge with grass pollen in local allergic rhinitis. J Allergy Clin Immunol 2009; 124: 1005-11.

8. Arasi S, Pajno GB, Lau S et al. Local allergic rhinitis: a critical reappraisal from a paediatric perspective. Pediatr Allergy Immunol 2016; 27: 569-73.

9. Smurthwaite L, Durham SR. Local IgE synthesis in allergic rhinitis and asthma. Curr Allergy Asthma Rep 2002; 2: 231-8.

10. Kato Y, Akasaki S, Muto-Haenuki Y, et al. Nasal sensitization with ragweed pollen induces local allergic-rhinitis-like symptoms in mice. PLoS One 2014; 9: e103540.

11. Rondón C, Bogas G, Barrionuevo E, et al. Nonallergic rhinitis and lower airway disease. Allergy 2017; 72: 24-34.

12. Samolinski B, Rapiejko P, Krzych-Falta E, et al. Standards of nasal allergen challenge. Postep Dermatol Alergol 2010; 27: 166-9.

13. Chen BW, Qu SH, Li M, et al. A murine model of local allergic rhinitis. Zhonghua Er Bi Yan Hou Tou Jing Wai Ke Za Zhi 2016; 51: 533-7.

14. Zicari AM, Occasi F, Di Fraia M, et al. Local allergic rhinitis in children: novel diagnostic features and potential biomarkers. Am J Rhinol Allergy 2016; 30: 329-34.

15. Buntarickpornpan P, Veskitkul J, Pacharn P, et al. The proportion of local allergic rhinitis to Dermatophagoides pteronyssinus in children. Pediatr Allergy Immunol 2016; 27: 574-9.

16. Gelardi M, Guglielmi AVN, Iannuzzi L, et al. Local allergic Rhinitis: entopy or spontaneous response? World Allergy Organ J 2016: 9: 39. 